Bu makaleye atıfta bulunmak için/To cite this article:

YAMAK, R. ERKAN, E. (2021). Kripto Para Getirilerinde Haftanın Gün Etkisi. Atatürk Üniversitesi Sosyal Bilimler Enstitüsü Dergisi, 25 (3), 1356-1372.

\title{
Kripto Para Getirilerinde Haftanın Gün Etkisi
}

\author{
Rahmi YAMAK ${ }^{* *}$ \\ Ece ERKAN ${ }^{(* *)}$
}

Öz: Bu çalışmada, kripto para piyasalarında haftanın gün etkisinin varlığı araştırılmıştır. Kripto para getirilerinde takvim anomalilerinin varliğına ilişkin yapılan ampirik çalışmalar incelendiğinde çoğu araştırmacının sadece Bitcoin piyasasına odaklandiğı görülmektedir. Bu çalışmada ise Bitcoin'in yanı sıra Ocak 2021 itibarıyla hem işlem hacmi hem de piyasa değeri açısından öne çıkan toplam on kripto para analiz edilmiştir. Kripto para birimleri farklı tarihlerde piyasaya sürüldüklerinden dolayı veri setinde ele alınan dönem farklllık göstermektedir. Tahmin edilen kukla değişkenli EKK, ARCH ve GARCH regresyon modelleri sonucunda haftanın her bir gününün farklı kripto para cinsleri üzerinde istatistiksel olarak anlamlı bir etkiye sahip oluğu tespit edilmiştir. Bulgular sekiz kripto para piyasasının etkin olmadı̆̆ını göstermektedir.

Anahtar Kelimeler: Kripto para, haftanın gün etkisi, etkin piyasa hipotezi

\section{The Day of the Week Effect on the Cryptocurrency Returns}

\begin{abstract}
In this study, the existence of the day of the week effect in cryptocurrency markets was investigated. When empirical studies on the existence of calendar anomalies in cryptocurrency returns are examined, it is seen that most researchers focus only on the Bitcoin market. In this study, we analyzed not only Bitcoin, but also ten other cryptocurrencies which stand out both in terms of trading volume and market size as of January 2021. Due to natural divergences in the launch dates of cryptocurrencies, the time frames taken into account in the data sets differ for each respective cryptocurrency. As a result of the estimated OLS with dummy variable, ARCH and GARCH regression models, it has been determined that each day of the week has a statistically significant effect on different cryptocurrencies. The findings show that eight cryptocurrency markets are not efficient.
\end{abstract}

Keywords: Cryptocurrency, day of the week effect, efficient market hypothesis

Makale Gelis Tarihi: 20.02.2021

Makale Kabul Tarihi: 23.09.2021

DOI: 10.53487/ataunisosbil.883979

\footnotetext{
(*) Prof. Dr., Karadeniz Teknik Üniversitesi İktisadi ve İdari Bilimler Fakültesi Ekonometri Bölümü (e-posta: yamak@ktu.edu.tr) (D) ORCID ID. https://orcid.org/0000-0002-2604-1797

${ }^{(* *)}$ Doktora Öğrencisi, Karadeniz Teknik Üniversitesi Sosyal Bilimler Enstitüsü Ekonometri Ana Bilim Dalı (e-posta: eceerkannn@gmail.com) (D) ORCID ID. https://orcid.org/0000-0002-37060774

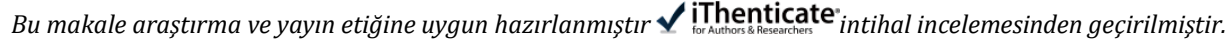




\section{Giriş}

Finansal varlık getirilerinin zamansal dağılımındaki takvim anomalilerinin etkisi uzun yıllardan beri ampirik literatürde araştırılan ve tartışılan konuların başında gelmektedir. Finansal getirilerde takvim anomalilerin bulunup bulunmadığının bilinmesi iki yönden önem teşkil etmektedir. Bunlardan birincisi Etkin Piyasa Hipotezi bir diğeri ise piyasadaki risk/getiri ilişkisi olarak ifade edilebilir. Bilindiği üzere Etkin Piyasa Hipotezi 1960'lı yılların sonlarında Eugene Fama tarafından ileri sürülmüştür. Hipoteze göre; alım-satıma konu olan finansal veya parasal varlıkların fiyatı o piyasaya ait halihazır tüm bilgiyi etkin bir biçimde yansıtmaktadır. Bundan dolayı da piyasa etkin olarak kabul edilmektedir (Fama, 1970). Bilginin fiyatlara yansıması veya Etkin Piyasa Hipotezinin geçerliliği varlık getirilerinde takvim etkilerinin bulunup bulunmamasına bağlıdır. Eğer getirilerde takvim anomalileri yani aykırı fiyat davranışları mevcutsa piyasa etkin olmamaktadır. Bu da normal üstü getirilere sebebiyet vermektedir. Tersi durumda ise piyasada risk olmamakta ve getiriler ise düşük düzeylerde seyretmektedir.

Getirilerdeki zaman serisi frekansına bağlı olarak farklı türlerde ortaya çıkma olasılığı bulunan takvim etkilerden biri haftanın gün etkisidir. Bu etki haftanın belli günlerinde pozitif belli günlerinde negatif veya bazı günlerde ortalamanın üstünde bazı günlerde ise altında ya da direk pazartesi, cuma gibi spesifik bir gün etkisi şeklinde olabilmektedir. Ampirik literatür, haftanın gün etkisini özellikle hisse senedi, tahvil ve bono gibi menkul varlıklar üzerinden araştıran çalışmalar yönünden oldukça zengindir. Bulgular genellikle haftanın gün etkisinin gerçekleştiği yönündedir. Örneğin; Cross (1973), French (1980), McFarland ve diğerleri (1982), Dubois ve Louvet (1996), Chen ve diğerleri (2000), Basher ve Sadorsky (2006), Ke ve diğerleri (2007), Güneysu ve Yamak (2011), Ariss ve diğerleri (2011), Abdioğlu ve Değirmenci (2013) ve Zhang ve diğerleri (2017) gibi yapılan birçok ampirik çalışmada finansal veya parasal varlıklarda haftanın gün etkisine ilişkin önemli kanıtlar elde edilmiştir.

Bilindiği üzere bilişim teknolojilerinin son 20 yıl içinde sahip olduğu gelişmelerin önemli etkilerinden biri de para piyasaları üzerinde görülmüş ve görülmeye de devam etmektedir. 2009 yılında Satoshi Nakamoto takma adıyla bilinen bir kişi ya da bir grup tarafından Bitcoin olarak isimlendirilen ve teknolojik para, kripto para veya dijital para olarak ifade edilen bir algoritma geliştirilmiştir. Bitcoin'in ardından çok sayıda açık kaynak kodlu kripto paralar çıkarılmış ve çıkarılmaya da devam etmektedir. Şöyle ki, 27 Kasım 2020 günü itibariyle kripto para piyasalarında 7793 farklı kripto para işlem görmektedir. Bu sayı her geçen gün artmaktadır. Kripto paraların işlem gördüğü piyasa sayısı ise yine aynı tarih itibariyle 33525 'tir. Bu piyasalarda işlem gören tüm kripto paraların piyasa değeri ise 500 milyar dolar civarındadır.

Kripto para geçmişinin kısa olmasından dolayı ilgili literatürde takvim anomalilerinin araştırıldığ 1 ampirik çalışma sayısı oldukça sınırlı sayıdadır. Bu sınırlı sayıdaki çalışmalarda kripto para piyasalarındaki haftanın gün etkisi araştırılırken analize genellikle Bitcoin başta olmak üzere birkaç kripto para dahil edilmiştir. Örneğin; Kurihara ve Fukushima (2017), Durai ve Paul (2018), Mbanga (2019), Decourt ve 
diğerleri (2019), Aharon ve Qadan (2019), Kinateder ve Papavassiliou (2019), Baur ve diğerleri (2019), Ma ve Tanizaki (2019) ve Evci (2020) tarafından yapılan çalışmalarda sadece Bitcoin üzerine yoğunlaşılmıştır. Robiyanto ve diğerleri (2019) ve Yılmaz ve Akkaya (2020) tarafından yapılan çalışmalarda ise Bitcoin'in yanı sıra Litecoin için de takvim anomalileri araştırılmıştır. Bu kripto para birimlerine ek olarak bazı çalışmalarda; Caporale ve Plastun (2019), Ripple ve Dash; Dangi (2020), EOS, Ethereum, Bitcoin Cash, Tether, XRP ve Stellar; Yaya ve Ogbonna (2019) ise Digibyte, Doge, Ethereum, Maidsafecoin, Monero, Nem, Stellar, Verge ve Vertcoin kripto para birimlerine yer verilmiştir.

Genellikle Bitcoin üzerine yoğunlaşan çalışmalar incelendiğinde takvim anomalisinin birçok çalışmada belirlenmesine rağmen hangi günlerde getirileri artırdığı ya da kayıpların yaşandığı hususunda literatürde ortak bir fikir birliğinin henüz oluşmadığı görülmektedir. Örneğin; Mbanga (2019)'nın çalışmasında fiyatlar cuma ve pazartesi günleri farklılaşmaktadır. Aharon ve Qadan (2019) ve Caporale ve Plastun (2019)'un çalışmalarında ise pazartesi günlerinin getirileri haftanın diğer günlerinden daha yüksektir. Salı ve çarşamba günlerindeki getirilerin daha yüksek olduğu ise Decourt ve diğerleri (2019) tarafından ortaya konulmuştur. Kinateder ve Papavassiliou (2019)'a göre ise çarşamba günlerinin getiriler üzerinde negatif yönlü bir etkisi mevcuttur. Evci (2020) tarafından yapılan bir başka çalışmada pazartesi, perşembe ve pazar günlerinin Bitcoin getirisini negatif etkilediği yönünde bulgular elde edilmiştir. Burada bulguların farklılaşmasında kripto para geçmişinin kısa olması ve analizlerde ele alınan dönemlerin değişkenlik göstermesi etkili bir faktör olarak değerlendirilebilir. Bu çalışmalara ek olarak Durai ve Paul (2018) ve Ma ve Tanizaki (2019) tarafından yapılan analizler sonucunda da Bitcoin piyasasının etkin olmadığı ortaya konulmuştur. Kurihara ve Fukushima (2017) tarafından yapılan bir başka çalışmada Bitcoin piyasasının etkin olmadığı ve dolayısıyla geleceğe yönelik Bitcoin getirilerinin rastgele bir dağılım göstereceği savunulmuştur. Yaya ve Ogbanna (2019), Dangi (2020) ve Yılmaz ve Akkaya (2020) gibi bazı çalışmalarda ise diğer çalışmaların aksine Bitcoin getirilerinde haftanın gün etkisine rastlanmamıştır.

Diğer Kripto para piyasalarına ilişkin yapılan çalışmalar incelendiğinde ise; Robiyanto ve diğerleri (2019)'ne göre Litecoin getirilerini pazartesi ve cuma günleri pozitif, çarşamba ise negatif yönde etkilemektedir. Ancak, Yılmaz ve Akkaya (2020) tarafından yapılan ampirik çalışmada Litecoin'in etkin piyasaya benzer özellik gösterdiği ifade edilmiştir. Benzer şekilde Caporale ve Plastun (2019) ve Yaya ve Ogbanna (2019) tarafından yapılan analizler sonucunda da Litecoin için haftanın gün etkisi bulunmamıştır. Caporale ve Plastun (2019)'ın bulgularına göre Ripple ve Dash kripto para getirilerinde haftanın günü etkisi yoktur. Dash için benzer bulgu Yaya ve Ogbanna (2019) tarafından desteklenmektedir. Ayrıca Yaya ve Ogbonna (2019)'nın çalışmasında Ethereum kripto para piyasasının da etkin olduğu belirlenmiştir.

Bu çalışmada Bitcoin'in yanı sıra kripto para piyasasında gerek işlem hacmi gerekse piyasa değeri itibariyle öne çıkan toplam on farklı kripto paranın getirilerindeki zamansal 
dağılımın haftanın günleri itibariyle farklılık gösterip göstermediği araştırılmıştır. Böylelikle Fama (1970) tarafından ileri sürülen Etkin Piyasa Hipotezi'nin kripto para piyasalarında geçerli olup olmadığı ortaya konulmuştur. İlgili hipotezin geçerli olmadığı kripto piyasalarında ise gün etkisinin yönü ve büyüklüğü belirlenmiştir. Analizde ele alınan dönem kripto paraların piyasaya çıkarıldığı tarih ile 10.01.2021 arasını kapsamaktadır. Çalışmanın ilerleyen aşamalarında veri seti ve ekonometrik yöntem tanıtılmış ardından bulgular sunulmuş ve son olarak ise sonuçlar değerlendirilmiştir.

\section{Veri Seti}

Çalışmada analize konu olan kripto paralar, 10.01.2021 günü itibariyle piyasa değeri en yüksek ilk 10 içinde yer alan Bitcoin, Ethereum, Ripple, Litecoin, Bitcoin Cash, Tether, Stellar, Cardano, Polkadot ve Chainlink'ten oluşmaktadır. Bu kripto paralar farklı tarihlerde piyasaya çıkarılmış olmalarından dolayı veri aralıkları da farklılık göstermektedir. Tablo 1'de çalı̧̧maya konu olan kripto paralara ilişkin genel bilgiler sunulmuştur. Analize konu olan on kripto para ilgili piyasanın yaklaşı \% $\% 5$ 'ini oluşturmaktadır. Bilindiği üzere ilk kez 2009 yılında piyasaya sürülen kripto para birimi Bitcoin olup piyasadaki güncel payı $\% 60$ 'tır. Analizde kullanılan ve en kısa geçmişi olan Polkadot ise 2020 yılında piyasaya çıkarılmış ve henüz yaklaşık \%2'lik bir paya ulaşmıştır. Ethereum, Litecoin'den dört yıl sonra piyasada işlem görmeye başlamasına rağmen Ocak 2021 itibariyle ilgili piyasadaki payı Litecoin'e kıyasla \%13 daha yüksektir. Tablo 1'deki ilk 4 satırda yer alan kripto paralarda madencilik işlemi varken diğerlerinde mevcut değildir. Ayrıca Ethereum, Tether ve Polkadot'ta ise maksimum arz sinırı bulunmamaktadır.

Tablo 1: Kripto Paralara İliş̧kin Göstergeler

\begin{tabular}{lccccc}
\hline \hline $\begin{array}{c}\text { Kripto } \\
\text { Para }\end{array}$ & $\begin{array}{c}\text { Piyasaya } \\
\text { Çıış Yılı }\end{array}$ & $\begin{array}{c}\text { Piyasa } \\
\text { Payı }\end{array}$ & $\begin{array}{c}\text { Madencilik } \\
\text { İşlemi }\end{array}$ & $\begin{array}{c}\text { Maksimum } \\
\text { Arz Sınırı }\end{array}$ & $\begin{array}{c}\text { Mevcut } \\
\text { Arz }\end{array}$ \\
\hline \hline Bitcoin & 2009 & 0.606 & VAR & 21 Milyon BTC & 18.6 Milyon BTC \\
Ethereum & 2015 & 0.140 & VAR & YOK & 114 Milyon ETH \\
Litecoin & 2011 & 0.008 & VAR & 84 Milyon LTC & 66.6 Milyon LTC \\
Bitcoin Cash & 2017 & 0.007 & VAR & 21 Milyon BCH & 18.6 Milyon BCH \\
Ripple & 2013 & 0.018 & YOK & 100 Milyar XRF & 99.9 Milyar XRP \\
Tether & 2014 & 0.021 & YOK & YOK & 32.1 Milyar USDT \\
Stellar & 2015 & 0.007 & YOK & 50 Milyar XLM & 50 Milyar XLM \\
Cardano & 2015 & 0.019 & YOK & 45 Milyar ADA & 45 Milyar ADA \\
Polkadot & 2020 & 0.018 & YOK & YOK & 1.04 Milyar DOT \\
Chainlink & 2017 & 0.008 & YOK & 1 Milyar LINK & 1 Milyar LINK \\
\hline \hline
\end{tabular}

\section{A. Bitcoin}

Şu an itibariyle, Bitcoin ve diğer kripto paralar geleneksel paralar gibi kripto piyasasından satın alınabileceği gibi bilgisayar üzerinden madencilik (mining) adı verilen işlemle de elde edilebilmektedir. Birçok kripto para gibi Bitcoin'de önceden belirlenmiş sınırlar dahilinde üretilmektedir. Protokol gereği Bitcoin'in arz sınırı 21 milyondur. Sistem bu miktardan fazlasının üretilmesine izin vermemektedir (Investopedia.com; Bitcoin.com). Bitcoin'de Ekim 2020 itibariyle 21 milyonluk arzın 
yaklaşık \%88'i üretilmiş olup, bu miktar değer olarak kripto piyasasının \%68'ine karş1lık gelmektedir. Ayrıca bu arz miktarının tamamının da kısa bir süre içerisinde üretilmesine izin verilmemektedir. Şöyle ki, Bitcoin kullanıma başlandığı ilk 4 yılda her on dakikada bir 50 Bitcoin oluşturacak şekilde bloklar oluşturmaktadır. Üretilen 50 Bitcoin'lik bloklar her 4 yılda bir yarıya düşürülmek suretiyle Bitcoin arzına kademeli bir sınırlama getirilmektedir.

\section{B. Litecoin}

Bir diğer kripto para olan Litecoin ise Bitcoin platformundaki bazı eksiklikleri gidermek amacıyla 2011 yılında geliştirilen eşler arası bir kripto paradır. Çalışma sistemi temelde Bitcoin'e benzemektedir. $\mathrm{Bu}$ nedenle Bitcoin protokolüne dayanılarak oluşturulmuştur. Genellikle de Bitcoin'in kardeşi olarak görülür ve dijital gümüş olarak adlandırılır. Ancak kullanılan algoritma yönünden Bitcoin'den farklılık göstermektedir. Litecoin'de madencilik algoritması bellek yoğun Scrypt kanıtını kullanmaktadır. Scrypt, GPU gibi basit donanımlarla bu tür paraların daha etkin üretilmesine veya ihraç edilmesine imkân vermektedir. Bu algoritma sayesinde Litecoin daha hılı onay ve daha etkin depolanma özelliğine sahiptir. Litecoin platformundaki algoritma madencilik işleminin kişisel bilgisayarlarla yapılabilmesine imkân tanımaktadır. Oysa Bitcoin platformunda kişisel bilgisayarlarla madencilik işlemi yapmak mümkün değildir. Bitcoin'de olduğu gibi Litecoin'de de toplam arzın bir sınırı vardır. Dolaşımda bulunabilecek toplam Litecoin adedi 84 milyon ile sınırlıdır. Nisan 2020 itibariyle bu miktarın yaklaşık \%77'lik kısmı üretilmiştir.

\section{Ripple}

Ripple platformunun başlangıç tarihi 2013 yılının sonudur. Kripto para birimi dışında da kullanılan Ripple, işlemlerin hızlı ve ucuz olması amacıyla oluşturulan açık kaynaklı bir protokoldür. Diğer kripto paralara göre oldukça hızlı işlem gerçekleşmektedir. Ayrıca daha düşük komisyonludur. Ancak, diğer kripto paralara kıyasla merkezi bir yapıya sahiptir. Ripple'de herhangi bir madencilik işlemi yoktur. Bu yönüyle Ripple, kendisinden daha eski olan Bitcoin ve Litecoin'den önemli ölçüde ayrışmaktadır. Madencilik yapılmamasından dolayı başlangıçta 100 milyar XRP'nin tamamı arz edilmiştir. Bu miktar maksimum arz miktarıdır. Ayrıca Ripple Labs toplam arzın \%61'ine başlangıçta sahip olmuştur. Ripple bu özelliğiyle bazı güvenlik endişelerini de beraberinde getirmiştir. Çünkü işlemlerin doğruluğu blok zinciri dışında kendisine has protokol algoritması tarafından sağlanmaktadır. İşlem gören her XRP sistemden silinmektedir. Ripple her ne kadar diğer kripto paraların çoğunda olduğu gibi sınırlı bir arz miktarına sahip olsa da asla merkeziyetçilikten bağımsız değildir.

\section{Ethereum}

Ethereum, blok zincir teknolojisini kullanan Ethereum platformundaki kripto paradır. Ethereum blok zincir tabanlı akıllı sözleşmelerin öncüsüdür. Blok zincir üzerinde akılllı bir sözleşme, belirli koşullarda otomatik çalışan bir programdır. Blok zincir içinde kod yazılımına imkân tanıyan bir kripto ağıdır. Bu platformda herkes kendi uygulamalarını merkeziyetsiz biçimde gerçekleştirebilmektedir. Bu platformun Bitcoin'den en önemli 
farkı bünyesinde akıllı sözleşmelerin bulunmasıdır. Bu sözleşmeler sayesinde taahhütler otomatik olarak gerçekleşmektedir. Ethereum platformu veya programı bu nedenle paranın ve ödemelerin güvenli interneti olarak adlandırılmaktadır. Herkese açık olan bu platformdaki işlemler hiçbir kişi veya kurum tarafından kontrol edilmeyen bir internettir. Bir diğer fark ise blokların üretilme süresiyle ilgilidir. Bitcoin'de bloklar ortalama 10 dakikada üretilirken Ethereum'da bu süre 15 saniyedir. Ayrıca Bitcoin'de arz 21 milyon BTC ile sınırlıyken Ethereum'da şu an itibariyle herhangi bir arz sınırı bulunmamaktadır. Ethereum ağ 30 Temmuz 2015'te 72 milyon ETH ile piyasaya girmiştir. Ancak birkaç yıl içerisinde ETHER ihracının azaltılacağı veya durdurulacağ 1 konusunda beklentiler oluşmuştur. Ethereum ile Bitcoin arasındaki bir diğer fark ise saniye başına düşen işlem sayısıdır. Bitcoin'de saniye başına 4 işlem yapılmaktadır. Ethereum'da ise işlem sayısı saniyede 15 'e çıkmaktadır.

Ethereum, bir platform ve dolayısıyla programlama dili olduğundan bu platform üzerinde başta finansal uygulamalar olmak üzere çeşitli uygulamalar geliştirilebilir. $\mathrm{Bu}$ platformda blok oluşturan madenciler Ethereum kripto parayla ödüllendirilir. Ethereum madenciliği GPU ile yani grafik kartlarıyla yapılmaktadır. Dolayısıyla Ethereum'da madencilik işlemlerini standart ev bilgisayarlarıyla yapmak mümkündür. Oysa Bitcoin madenciliği yüksek donanımlı bilgisayarlara ihtiyaç duymaktadır.

\section{E. Bitcoin Cash}

Kripto paralarının ilki ve öncüsü olan Bitcoin'in zamanla bazı eksiklikleri görülmeye başlanmıştır. Daha doğrusu teknik anlamda yetersiz kaldığı görülmüştür. Özellikle de kapasite anlamında olumsuzluklar yaşanmaya başlamıştır. Şöyle ki, Bitcoin'de işlem kapasitesinin belli bir sınırı vardı. İşlem blokları $1 \mathrm{MB}$ ile sınırlı olduğundan işlemler daha fazla zaman almakta ve dolayısıyla da bu, işlem kapasitesinin düşmesine neden olmaktadır. Bitcoin ağının kapasitesi saniyede sadece 7 işleme müsaade edecek kapasitede bulunmaktaydı. Kapasite düşüklüğü sadece işlem hacmini sınırlandırmamakta aynı zamanda işlem maliyetlerinin de yükselmesine yol açmaktaydı. Bitcoin'de yaşanan bu olumsuzluklar ve deneyimler 1şı̆̆ında alternatif bir kripto para olarak Bitcoin Cash geliştirilmiş ve 2017 yılının Temmuz ayında işlem görmeye başlamıştır. Bitcoin Cash'in kısaltması BCH'dir. Kuşkusuz bu kripto para da Bitcoin ailesinin bir üyesidir. Bitcoin platformundaki blok zincirden ayrılarak oluşturulmuş yeni ve farklı bir kripto para birimdir. Bitcoin Cash 1 MB ile sınırlı olan Bitcoin blok boyutunu 8 kat artırmış̧ır. Dolayısıyla Bitcoin Cash Bitcoin'den daha hızlı ve ucuz bir işlem platformudur. Bugün itibariyle Bitcoin Cash'deki işlem maliyeti yaklaşı 50 centtir. Aynı işlemin maliyeti Bitcoin'de yaklaşık 2 dolardır.

Bitcoin'de olduğu gibi bu kripto parada da madencilik işlemi yapılmaktadır. Madenciler üretmiş oldukları her blok için ödül kazanmaktadırlar. Başlangıçta $12.5 \mathrm{BCH}$ olan ödül yarılanma ile $6.25 \mathrm{BCH}$ olacaktır. Bitcoin Cash'de de toplam arz sınırlıdır. O da 21 milyon BCH ile sınırıdır. 2020 Nisan ayı itibariyle bu arzın yaklaşık \%88 üretilmiş ve toplam arza dahil edilmiştir.

\section{F. Tether}


Tether, Bitcoin blok zincirinde üretilen bir kripto para birimidir. Temmuz 2014'te Hong Kong merkezli Tether şirketi tarafından piyasaya sürülmüştür. Tether'in para birimi USDT olarak tanımlanmıştır. Bu kripto parayı diğer kripto paralardan ayıran en önemli özellik değerinin 1'e 1 oranıla ABD dolarına sabitlenmiş olmasıdır. Bu özelliğiyle Tether şu an itibariyle kripto para piyasasının en istikrarlı para birimidir. Kripto para piyasasında en düşük oynaklığa sahip olan kripto paradır. Bu nedenle risk seviyesi düşük güvenli bir yatırım aracı olma özelliğine sahiptir. Arz edilen her Tether için rezerv olarak tutulan eşdeğer miktarda $\mathrm{ABD}$ doları vardır. Bu kripto parada madencilik işlemi yoktur. Ayrıca arz sınırı da bulunmamaktadır. 2021 Şubat ayı itibariyle toplam arzı yaklaşık 32 milyar USDT'dir. Bunun neredeyse tamamı dolaşımdadır.

\section{G. Stellar}

Bu kripto para Stellar Vakfı tarafından geliştirilmiştir. Protokol ağı 2015 yılının sonunda faaliyet geçen Stellar, kripto para borsalarında XLM sembolü altında işlem görmektedir. Stellar'ın para birimi Lümen'dir. Herhangi bir para birimi çifti arasında sınır ötesi işlemlere izin veren açık kaynaklı, merkezi olmayan bir protokoldür. Teknik olarak Ripple'ye benzer bir çalışma şekline sahiptir. Diğer kripto paralara kıyasla transfer işleminde maliyet avantajına sahiptir. Bu kripto parada madencilik işlemi yoktur. Açık kaynaklı merkezi olmayan bu protokol bir yandan işlem maliyeti düşük seviyede diğer yandan da transfer süresi kısaltılma amacı taşımaktadır. Stellar'da maksimum arz sınırı bulunmaktadır. O da 50 milyar Lümen'dir. Bu maksimum arzın tamamı piyasaya arz edilmiştir. Stellar'ın 2021 Şubat ayı itibariyle dolaşımdaki XLM miktarı toplam arzın $\% 45$ 'i kadardir.

\section{H. Cardano}

Cardano, kripto para piyasasının ilk hakemli blok zinciridir. Bu kripto para 2015 yılında Cardano Vakfı tarafından geliştirilmiştir. Para birimi ADA olan Cardano, kripto para göndermek ve almak için kullanılabilecek kripto sistemine sahip bir platformdur. Cardano'dan sorumlu kâr amacı gütmeyen vakıf, protokollerini yayınlanmadan önce gözden geçirilmesi için Edinburgh Üniversitesi ve Tokyo Teknoloji Enstitüsü gibi çeşitli üniversitelerden akademisyen ve bilim adamlarından oluşan bir ă̆ oluşturmuştur. Cardano platformu, ikinci nesle ait olan Bitcoin'in, birinci nesil bir madeni paranın ve Ethereum'un ölçeklendirme sorunlarını iyileştirdiğini iddia eden üçüncü nesil bir kripto para birimi ve akıllı sözleşme platformudur. Bu kripto parada madencilik işlemi yoktur. Ancak maksimum arz sınırına sahiptir. O da 45 milyar ADA'dır. 2021 Şubat itibariyle bu arzın yaklaşık \%69'u dolaşımdadır.

\section{Polkadot}

2020 yılında İsviçre merkezli Web3 vakfı tarafından geliştirilmiş ve piyasaya sürülmüş yeni nesil bir kripto paradır. En önemli teknik özelliği çok sayıdaki blok zincirini tek bir ağa bağlayabilmesidir. Polkadot tasarımının esas amacı birkaç zinciri 
desteklemektir. Tek başına var olan tek bir blok zinciri değildir. Bu özelliğiyle Polkadot'ta her tür veri diğer kripto paralara kıyasla daha etkin biçimde blok zincir aktarımları yapılabilmektedir. Polkadot'ta iki tür blok zinciri bulunmaktadır. Bunlardan biri işlemlerin kalıcı olduğu aktarma zinciri adı verilen ana ağdır. Diğeri ise parachain adı verilen kullanıcı tarafından oluşturulan ağlardır. Polkadot, madenciliği yapılan bir kripto para türü değildir. Maksimum arz miktarı bulunmayan Polkadot'un toplam arzı 1 milyar DOT'tur. 2021 Şubat itibariyle dolaşımdaki arzı ise yaklaşık 900 milyon DOT'tur.

\section{J. Chainlink}

Chainlink, Ethereum altyapısıyla geliştirilmiş blok zincir projesidir. Para birimi LINK'tir. 2017 yılında piyasaya sürülen Chainlink farklı ödeme sistemleri ve bankalar ile blok zincir arasında köprü oluşturmaya imkân tanıyan bir kripto para platformudur. Platform, zincir dışında bulunan bir veriyi akıllı kontratlar vasıtasıyla blok zincire aktarılmasını sağlar. Chanlink’te madencilik işlemi yapılmamaktadır. LINK üretimi ve piyasaya sürümü tamamen Chainlink şirketi tarafından yapılmaktadır. Bununla beraber Chainlink'in önceden belirlenmiş maksimum arz miktarı bulunmaktadır. $\mathrm{O}$ da 1 milyar LINK'tir. Bunun tamamı üretilmiş olup piyasaya sürülmüştür. 2021 Şubat ayı itibariyle dolaşımda olan miktarı yaklaşık 406 Milyon LINK'tir.

\section{Yöntem}

Çalışmada öncelikle her bir kripto para birimi için getiri serisi elde edilmiştir. Getiri oranları hesaplanırken aşağıdaki fiyat serileri kullanılmıştır.

$$
\begin{array}{ll}
P_{t}^{C} & : t \text { günün kapanış fiyatı } \\
P_{t-1}^{C} & : t-1 \text { günün kapanış fiyatı }
\end{array}
$$

Getiri oranı (R), bir önceki günün kapanış fiyatı ile bir sonraki günün kapanış fiyatı arasındaki değişismi göstermekte olup (1) numaralı eşitlikle ifade edilmiştir. İlgili oran hesaplanırken fiyat serisi logaritmik transformasyona tabi tutulmuştur.

$$
R_{t}=\log P_{t}^{C}-\log P_{t-1}^{C}
$$

İlk önce cevaplandırılması gereken soru kripto getirisinde gün etkisi var mıdır? Diğer bir ifadeyle kripto getirilerinde günler itibariyle istatistiksel olarak anlamlı bir fark var mıdır? Bu soruyu cevaplandırmak için getiriler iki farklı şekilde test edilmiştir. İlk olarak (2) numaralı eşitlikteki sabit terimli regresyon denklemi her bir günü temsil eden kukla değişken $\left(D_{i t}\right)$ için ayrı ayrı tahmin edilmiştir. Burada haftanın belirli bir gününün ortalama getirisi ile geri kalan altı gününün ortalama getirisi arasında istatistiksel olarak anlamlı bir fark olup olmadığı kukla değişken katsayısına ilişkin t-testi kullanılarak sınanmaktadır. Örneğin sadece pazartesi kukla değişkeni modele katıldığından kukla değişken katsayısının istatistiksel olarak anlamlı olması pazartesi etkisi olduğunu aksi 
taktirde olmadığı anlamına gelmektedir. Kukla değişken katsayısının istatistiksel olarak anlamlı olup olmadığı t-testi ile belirlenmektedir.

$$
R_{t}=\beta_{0}+\beta_{1} D_{i t}
$$

Çalışmada haftanın gün etkisinin varlığı (3) numaralı eşitlikteki regresyon denklemi sabit terimsiz şekilde EKK ile tahmin edilerek sınanmaya devam edilmiştir. Sabit terimsiz bu regresyon denklemindeki kukla değişken katsayıları temsil ettiği günün ortalama getirisini ifade etmektedir. Güneysu ve Yamak (2011:38) tarafindan yapılan çalışmada da olduğu gibi ilgili katsayıların istatistiksel olarak birbirine eşit olup olmadığının sınanması kripto getirisinde gün etkisinin olup olmadığının test edilmesi demektir. Eğer bu regresyon denkleminde tüm katsayıların birbirine eşit olduğunu ifade eden $\mathrm{H}_{0}$ hipotezi reddedilmişse bu kez hangi gün veya günlerin etkisinin bulunduğunu belirlemek için (2) numaralı eşitlikteki regresyon denkleminden ve katsayıların t-test istatistiklerinden yararlanılmaktadır.

$$
R_{t}=\beta_{1} D 1_{t}+\beta_{2} D 2_{t}+\beta_{3} D 3_{t}+\beta_{4} D 4_{t}+\beta_{5} D 5_{t}+\beta_{6} D 6_{t}+\beta_{7} D 7_{t}
$$

Geleneksel ekonometrik modellerde, hata teriminin varyansının sabit olduğu varsayılır. Fakat günlük frekanslı gözlemlerin sıklıkla kullanıldığı finansal zaman serilerinde genellikle değişen varyans problemiyle karşılaşılmaktadır. Aynı zamanda farklı dönemler boyunca gözlemlenen değisşen varyans otokorelasyonlu da olabilmektedir. Böyle bir durumda da $t$ ve $\mathcal{X}^{2}$ testleri güvenirliliğini kaybetmektedir. $\mathrm{Bu}$ bakımdan çalışmada değişen varyans sorunundan kaçınmak için eşitlik (3)'te verilen kukla değişkenli regresyon modeli Engle (1982) tarafindan ileri sürülen ARCH (otoregresif koşullu değişen varyans) ve Bollerslev (1986) tarafindan geliştirilen GARCH (genelleştirilmiş otoregresif koşullu değişen varyans) yöntemleri altında da tahmin edilmiştir.

\section{Bulgular}

Eşitlik (1) kullanılarak on kripto para için türetilen getiri serilerinin tanıtıcı istatistikleri Tablo 2'de sunulmuştur. İlgili Tablo incelendiğinde piyasaya çıkışından 10 Ocak 2021'e kadar geçen sürede en yüksek günlük ortalama getiri 0.0087 ile Polkadot; en düşük günlük ortalama getiri ise Tether ve Bitcoin Cash kriptolarına aittir. Gerek işlem hacmi gerekse piyasa değeri itibariyle öne çıkan on kripto para içerisinde gün içi en yüksek kazanç ortalaması 1.0275 olarak Ripple'den sağlanmıştır. En yüksek kayıp ise Ripple ve Chainlink'te gerçekleşmiştir. Son olarak sapma değerlerine bakıldığında genellikle kripto paralardaki sapmaların 0.07 civarlarında seyrettiği Tablo 2'den görülmektedir. En yüksek sapma oranı Chainlink getiri serisinde 0.0776 olarak belirlenmiştir. Tether getirisindeki sapma ise diğerlerine kıyasla oldukça düşüktür. $\mathrm{Bu}$ da Tether kriptosunun risk seviyesinin düşük ve güvenli bir yatırım aracı olduğunu göstermektedir. Tether'den sonra ilgili kripto paralar arasında Bitcoin'in de risk seviyesi 
diğerlerine kıyasla düşüktür. Ethereum ve Litecoin ise risk düzeyleri açısından birbirlerine oldukça yakındır.

Tablo 2: Kripto Para Getirilerine İlişkin Tanıtıcı İstatistikler

\begin{tabular}{lcccc}
\hline \hline Kripto Para & Ortalama & Sapma & En Yüksek & En Düşük \\
\hline \hline Bitcoin & 0.0020 & 0.0424 & 0.3575 & -0.4647 \\
Ethereum & 0.0038 & 0.0618 & 0.4124 & -0.5507 \\
Ripple & 0.0015 & 0.0714 & 1.0275 & -0.6164 \\
Litecoin & 0.0013 & 0.0630 & 0.8289 & -0.5139 \\
Bitcoin Cash & 0.0002 & 0.0739 & 0.4316 & -0.5614 \\
Tether & $2 * 10^{-20}$ & 0.0058 & 0.0572 & -0.0491 \\
Stellar & 0.0020 & 0.0741 & 0.7231 & -0.4100 \\
Cardano & 0.0023 & 0.0738 & 0.8612 & -0.5037 \\
Polkadot & 0.0087 & 0.0757 & 0.4418 & -0.2231 \\
Chainlink & 0.0038 & 0.0776 & 0.4841 & -0.6175 \\
\hline \hline
\end{tabular}

Eşitlik (2) kullanılarak haftanın her bir günü için ayrı ayrı koşulan sabit terimli ve kukla değişkenli regresyon modellerinin sonuçları Tablo 3'te verilmiştir. Tahmin edilen modeller ile haftanın belirli bir günün ortalama getirisi ile geri kalan altı günün ortalama getirisi arasında istatistiksel olarak anlamlı bir fark olup olmadığı t-istatistik değeri kullanılarak sınanmıştır. Bu bağlamda Bitcoin, Bitcoin Cash, Tether ve Cardano getirilerinde haftanın gün etkisinin olduğu saptanmıştır. Bitcoin'de pazartesi günü etkisi mevcuttur. Pazartesi günlerinin ortalama getirisinin diğer günlerin ortalama getirisinden 0.0054 daha fazla olduğu tespit edilmiş̧ir. Diğer günlerin getirisinde ise istatistiksel olarak anlamlı bir fark gerçekleşmemiştir. Bir diğer kripto para birimi olan Tether'de pazartesi günlerinin ortalama getirisi diğer günlerden istatistiksel olarak $\% 10$ anlamlllık düzeyinde farklı olup, pazartesi günleri kayıplar gerçekleşmektedir. Bitcoin Cash incelendiğinde ise perşembe günlerinin ortalama getirisi \%1 anlamlılık düzeyinde diğer günlerden 0.0167 daha düşüktür. Cuma ve cumartesi günlerinin ortalama getirisi ise diğer günlere kıyasla artmaktadır. Perşembe ve cumartesi günü etkisi Cardano kripto para biriminde de belirlenmiş olup, Bitcoin Cash'e benzer olarak perşembe günleri kayıplar olurken cumartesi günleri getiriler artmaktadır.

Tablo 3: EKK Regresyon Modeli Sonuçları I

\begin{tabular}{|c|c|c|c|c|c|c|c|}
\hline Kripto Para & Pazartesi & Salı & Çarşamba & Perşembe & Cuma & Cumartesi & Pazar \\
\hline Bitcoin & $0.0054^{b}$ & 0.0003 & -0.0022 & -0.0022 & -0.0004 & 0.0012 & - -0.0021 \\
\hline Ethereum & -0.0021 & 0.0011 & 0.0002 & -0.0003 & -0.0011 & 0.0024 & -0.0002 \\
\hline Ripple & -0.0016 & 0.0005 & -0.0017 & 0.0029 & 0.0052 & -0.0034 & -0.0020 \\
\hline Litecoin & $6^{*} 10^{-6}$ & 0.0025 & -0.0037 & -0.0037 & 0.0005 & 0.0047 & -0.0003 \\
\hline Bitcoin Cash & -0.0031 & -0.0003 & -0.0005 & $-0.0167^{a}$ & $0.0120^{b}$ & $0.0102^{\mathrm{c}}$ & -0.0016 \\
\hline Tether & $-0.0006^{c}$ & $1 * 10^{-5}$ & $3 * 10^{-5}$ & 0.0004 & 0.0001 & 0.0001 & 0.0001 \\
\hline Stellar & 0.0049 & -0.0036 & 0.0012 & -0.0025 & 0.0009 & 0.0012 & -0.0023 \\
\hline Cardano & 0.0001 & 0.0015 & -0.0052 & $-0.0107^{c}$ & 0.0041 & $0.0136^{b}$ & -0.0034 \\
\hline Polkadot & 0.0099 & -0.0004 & -0.0071 & -0.0014 & -0.0160 & 0.0182 & -0.0039 \\
\hline Chainlink & -0.0062 & 0.0042 & -0.0033 & -0.0043 & 0.0028 & $0.0127^{\mathrm{b}}$ & -0.0059 \\
\hline
\end{tabular}


Eşitlik (3) kullanılarak tahmin edilen kukla değişkenli regresyon denklemlerinin sonuçları Tablo 4 'te; modellerin tanısal istatistikleri ise Tablo 5 'te verilmiştir. Tablo 5 'te verilen $\mathcal{X}^{2}$ istatistiği yardımıyla günlerin ortalama getirilerinin birbirlerine eşit olduğunu ifade eden $H_{0}: \beta_{1}=\beta_{2}=\beta_{3}=\beta_{4}=\beta_{5}=\beta_{6}=\beta_{7}$ hipotezi sınanmıştır. On kripto para içerisinden sadece Bitcoin Cash getiri modelinin $\mathrm{H}_{0}$ hipotezi $\% 5$ anlamlılık düzeyinde reddedilmiştir. Diğer tüm kripto para getiri modellerinde günlerin ortalama getirilerinin birbirine eşit olduğu tespit edilmiştir. Fakat ARCH test sonuçlarına göre tüm modellerde değişen varyans problemi olduğu belirlenmiştir. Bu nedenle de modellere ilişkin hesaplanan $t$ ve $\mathcal{X}^{2}$ istatistiklerinin olasılık değerleri gerçeği yansıtmamaktadır. İlgili sorunu gidermek amacıyla analizin bir sonraki aşamasında ARCH (1) ve GARCH $(1,1)$ getiri modellerinin tahminine geçilmiştir.

Tablo 4: EKK Regresyon Modeli Sonuçları II

\begin{tabular}{lccccccc}
\hline \hline Kripto Para & Pazartesi & \multicolumn{1}{c}{ Salı } & Çarşamba Perşembe & Cuma & Cumartesi & Pazar \\
\hline \hline Bitcoin & $0.0066^{\mathrm{a}}$ & 0.0023 & 0.0001 & 0.0001 & 0.0017 & 0.0031 & 0.0002 \\
Ethereum & 0.0019 & 0.0047 & 0.0039 & 0.0035 & 0.0028 & 0.0059 & 0.0036 \\
Ripple & 0.0001 & 0.0019 & $3^{*} 10^{-5}$ & 0.0041 & $0.0059^{\mathrm{c}}$ & -0.0014 & -0.0002 \\
Litecoin & 0.0013 & 0.0035 & -0.0019 & -0.0019 & 0.0017 & $0.0054^{\mathrm{c}}$ & 0.0010 \\
Bitcoin Cash & -0.0024 & -0.0001 & -0.0003 & $-0.0141^{\mathrm{b}}$ & $0.0105^{\mathrm{c}}$ & 0.0089 & -0.0011 \\
Tether & -0.0005 & $9^{*} 10^{-6}$ & $2^{*} 10^{-5}$ & 0.0003 & 0.0001 & 0.0001 & -0.0001 \\
Stellar & 0.0063 & -0.0010 & 0.0031 & -0.0001 & 0.0029 & 0.0031 & $5^{*} 10^{-5}$ \\
Cardano & 0.0024 & 0.0036 & -0.0021 & -0.0068 & 0.0058 & $0.0139^{\mathrm{b}}$ & -0.0006 \\
Polkadot & 0.0172 & 0.0083 & 0.0025 & 0.0074 & -0.0051 & 0.0242 & 0.0053 \\
Chainlink & -0.0015 & 0.0074 & 0.0010 & 0.0002 & 0.0063 & $0.0147^{\mathrm{b}}$ & -0.0013 \\
\hline \hline Not: $^{\text {a }}{ }^{b}{ }^{\text {ve }}{ }^{c}$ sirasiyla; $\% 1, \% 5$ ve \%10 anlamlılık düzeylerini ifade etmektedir. \\
\multicolumn{7}{c}{ Tüm getiri serileri ADF ve PP birim kök testlerine göre seviyesinde durağandır }
\end{tabular}

Tablo 5: EKK Regresyon Modelleri II Tanısal İstatistikler

\begin{tabular}{lccc}
\hline \hline Kripto Para & $\boldsymbol{X}^{\mathbf{2}}$ & DW & ARCH (1) \\
\hline \hline Bitcoin & 7.3332 & 2.0177 & $118.0436^{\mathrm{a}}$ \\
Ethereum & 0.7199 & 1.9381 & $45.9921^{\mathrm{a}}$ \\
Ripple & 3.2149 & 1.9216 & $199.6985^{\mathrm{a}}$ \\
Litecoin & 4.2424 & 1.9765 & $107.3894^{\mathrm{a}}$ \\
Bitcoin Cash & $13.2296^{\mathrm{b}}$ & 1.8662 & $52.5972^{\mathrm{a}}$ \\
Tether & 3.7333 & 2.7203 & $356.0130^{\mathrm{a}}$ \\
Stellar & 2.3996 & 1.8751 & $309.2408^{\mathrm{a}}$ \\
Cardano & 8.2526 & 2.0034 & $42.4204^{\mathrm{a}}$ \\
Polkadot & 1.9174 & 1.9909 & $7.4206^{\mathrm{a}}$ \\
Chainlink & 6.0958 & 2.0249 & $17.0082^{\mathrm{a}}$ \\
\hline \hline Not: ${ }^{\text {ab }}$, ve $^{c}$ sirastyla; \%1, \%5 ve \%10 anlamlillk düzeylerini \\
ifade etmektedir.
\end{tabular}


ARCH (1) model sonuçları Tablo 6'da tanısal istatistikler ise Tablo 7'de sunulmuştur. Hesaplanan $\mathcal{X}^{2}$ istatistiklerine göre Bitcoin, Ripple, Litecoin, Bitcoin Cash, Stellar ve Cardano getirilerinde günlerin ortalama değerleri birbirlerine eşit değildir. $\mathrm{Bu}$ durumda gün etkisinin varlığından söz edilebilmektedir. ARCH LM test sonuçlarına göre tüm modellerde değişen varyans probleminin giderildiği görülmektedir. DW test istatistik değerleri ise ikiye oldukça yakın olup, Tether dışındaki tüm getiri modellerinde otokorelasyon problemi mevcut değildir. Bitcoin getiri modelinde pazartesi günlerini ifade eden kukla değişkenin katsayı 0.0066 ve \%1 anlamlılık düzeyinde istatistiksel olarak anlamlı bulunmuştur. Ripple getirisinde pazartesi, çarşamba, perşembe, cuma ve cumartesi günlerinin etkisi mevcuttur. Çarşamba günleri getiriler artarken, diğer günlerde (pazartesi-perşembe-cuma-cumartesi) ortalama getiriden kayılar mevcuttur. Çarşamba, perşembe ve pazar günlerinin etkisi ise Litecoin getirilerinde görülmektedir. Ripple'de olduğu gibi Litecoin'de de çarşamba günleri getiriler artmaktayken perşembe günleri azalmaktadır. Pazar gününün katsayısı ise 0.0091 olup \%1 anlamlılık düzeyinde istatistiksel olarak anlamlıdır. Bitcoin Cash'de sadece perşembe etkisi görülmekte olup etkinin yönü diğer getirilerde olduğu gibi negatiftir. Stellar getirisinde salı ve pazar günleri kayıplar yaşanmaktadır. Son olarak Cardona getirisi ise perşembe günleri ortalamanın altındayken cuma ve cumartesi günleri ortalamanın üstüne çıkmaktadır.

Tablo 6: ARCH (1) Model Sonuçları

\begin{tabular}{lccccccc}
\hline \hline Kripto Para & Pazartesi & Salı & Çarşamba & Perşembe & Cuma & Cumartesi & Pazar \\
\hline \hline Bitcoin & $\mathbf{0 . 0 0 6 6}^{\mathbf{a}}$ & 0.0023 & 0.0001 & 0.0001 & 0.0017 & 0.0031 & 0.0002 \\
Ethereum & 0.0009 & 0.0036 & 0.0018 & -0.0026 & 0.0027 & $0.0068^{\mathrm{c}}$ & 0.0031 \\
Ripple & $\mathbf{- 0 . 0 0 3 1}^{\mathbf{c}}$ & 0.0001 & $\mathbf{0 . 0 0 3 7}^{\mathbf{a}}$ & $\mathbf{- 0 . 0 0 8 5}^{\mathbf{a}}$ & $\mathbf{- 0 . 0 0 6 8}^{\mathbf{a}}$ & $\mathbf{- 0 . 0 1 1 4}^{\mathbf{a}}$ & -0.0023 \\
Litecoin & 0.0002 & 0.0026 & $\mathbf{0 . 0 0 3 2}^{\mathbf{c}}$ & $\mathbf{- 0 . 0 0 5 1}^{\mathbf{b}}$ & 0.0015 & 0.0035 & $\mathbf{0 . 0 0 9 1}^{\mathbf{a}}$ \\
Bitcoin Cash & 0.0034 & -0.0019 & 0.0011 & $\mathbf{- 0 . 0 1 5 5}^{\mathrm{a}}$ & 0.0062 & 0.0081 & -0.0012 \\
Tether & 0.0001 & 0.0003 & $0.0003^{\mathrm{a}}$ & $0.0005^{\mathrm{a}}$ & $0.0004^{\mathrm{b}}$ & 0.0002 & $3^{*} 10^{-5}$ \\
Stellar & 0.0044 & $\mathbf{- 0 . 0 0 6 5}^{\mathbf{b}}$ & 0.0022 & -0.0032 & -0.0017 & -0.0021 & $\mathbf{- 0 . 0 0 8 4}^{\mathrm{a}}$ \\
Cardano & 0.0002 & -0.0073 & 0.0007 & $\mathbf{- . 0 0 8 3}^{\mathbf{c}}$ & $\mathbf{0 . 0 0 7 2}^{\mathbf{c}}$ & $\mathbf{0 . 0 1 0 9}^{\mathbf{c}}$ & -0.0034 \\
Polkadot & 0.0144 & -0.0048 & $0.0158^{\mathrm{c}}$ & 0.0116 & 0.0029 & 0.0101 & $0.0259^{\mathrm{b}}$ \\
Chainlink & -0.0006 & 0.0064 & $0.0086^{\mathrm{c}}$ & -0.0009 & 0.0034 & $0.0121^{\mathrm{b}}$ & -0.0006 \\
\hline \hline
\end{tabular}

Not: ${ }^{a},{ }^{b}$ ve ${ }^{c}$ sirastyla; $\% 1, \% 5$ ve \%10 anlamllltk düzeylerini ifade etmektedir.

Tüm getiri serileri ADF ve PP birim kök testlerine göre seviyesinde durağandır

Tablo 7: ARCH (1) Modeli Tanısal İstatistikler

\begin{tabular}{lccc}
\hline \hline Kripto Para & \multicolumn{1}{c}{$\boldsymbol{X}^{\mathbf{2}}$} & DW & ARCH (1) \\
\hline \hline Bitcoin & $\mathbf{1 2 . 7 1 4 4}^{\mathbf{b}}$ & 2.0177 & 0.0082 \\
Ethereum & 5.0453 & 1.9369 & 0.7687 \\
Ripple & $\mathbf{1 3 5 . 4 1 5 3}^{\mathbf{a}}$ & 1.9076 & 0.6249 \\
Litecoin & $\mathbf{2 4 . 9 9 1 5}^{\mathbf{a}}$ & 1.9796 & 0.3911 \\
Bitcoin Cash & $\mathbf{2 7 . 3 9 3 5}^{\mathbf{a}}$ & 1.8668 & 0.0824 \\
Tether & 5.5961 & 2.7157 & 0.0602 \\
Stellar & $\mathbf{2 3 . 0 0 0 5}^{\mathbf{a}}$ & 1.8696 & 0.4962 \\
Cardano & $\mathbf{1 4 . 4 6 8 6}^{\mathbf{b}}$ & 2.0038 & 0.2261 \\
Polkadot & 5.0329 & 1.9909 & 0.4794
\end{tabular}




\begin{tabular}{|c|c|c|c|}
\hline Chainlink & 5.4424 & 2.0252 & 0.0756 \\
\hline
\end{tabular}

Bir sonraki aşamada tahmin edilen GARCH $(1,1)$ model sonuçları Tablo 8'de; tanımlayıcı istatistikleri ise Tablo 9'da sunulmuştur. Hesaplanan $\mathcal{X}^{2}$ istatistikleri incelendiğinde günlerin ortalama getirilerinin birbirlerine eşit olduğunu ifade eden $\mathrm{H}_{0}$ hipotezi Bitcoin, Ethereum, Litecoin, Chainlink ve Cardano için reddedilmiştir. ARCH (1) modellerine ek olarak Ethereum ve Chainlink ortalama getirilerinde de haftanın gün etkisi olduğu GARCH $(1,1)$ modelleri ile ortaya konulmuştur. Tam tersi olarak Ripple, Bitcoin Cash ve Stellar ortalama getirilerinde $\mathrm{ARCH}$ (1) modellerinde gün etkisi saptanmasına karşın GARCH $(1,1)$ modellerinde mevcut değildir. GARCH $(1,1)$ Bitcoin Cash getiri modelinde $\% 5$ ve Cardona getiri modelinde ise $\% 10$ anlamlılık düzeyinde değişen varyans problemi tespit edilmiştir. Bu bakımdan yorumlamada ARCH (1) modelleri dikkate alınmıştır. Katsayılar ve yönleri her iki modelde de benzerlik göstermektedir. Daha önce Bitcoin için tespit edilen pazartesi günü etkisine ek olarak GARCH $(1,1)$ modelinde salı, cuma ve cumartesi etkileri de saptanmıştır. Ethereum'un ortalama getirisi salı ve cumartesi günleri artarken perşembe günleri azalmaktadır. Litecoin için ARCH (1) modelindeki çarşamba günlerinin pozitif etkisi GARCH $(1,1)$ modellerinde negatif olarak tespit edilmiştir. Chainlink ortalama getirisi ise salı ve cumartesi günleri artmaktadır. Tether dışındaki tüm getiri modellerinin DW istatistikleri ikiye oldukça yakın olup, modellerde otokorelasyon problemi mevcut değildir.

Tablo 8: GARCH $(1,1)$ Model Sonuçları

\begin{tabular}{lccccccc}
\hline \hline Kripto Para & Pazartesi & Salı & Çarşamba & Perşembe & Cuma & Cumartesi & Pazar \\
\hline \hline Bitcoin & $\mathbf{0 . 0 0 4 4}^{\mathbf{a}}$ & $\mathbf{0 . 0 0 2 8}^{\mathbf{b}}$ & 0.0001 & -0.0016 & $\mathbf{0 . 0 0 2 8}^{\mathbf{c}}$ & $\mathbf{0 . 0 0 3 1}^{\mathbf{c}}$ & 0.0011 \\
Ethereum & 0.0026 & $\mathbf{0 . 0 0 4 9}^{\mathbf{c}}$ & -0.0018 & $\mathbf{- 0 . 0 0 4 8}$ & 0.0035 & $\mathbf{0 . 0 0 7 4}^{\mathbf{b}}$ & 0.0031 \\
Ripple & -0.0020 & -0.0008 & $-0.0056^{\mathrm{a}}$ & $-0.0064^{\mathrm{a}}$ & 0.0009 & -0.0004 & -0.0031 \\
Litecoin & -0.0032 & 0.0007 & $\mathbf{- 0 . 0 0 4 5}^{\mathbf{b}}$ & $\mathbf{- 0 . 0 0 4 8}^{\mathbf{b}}$ & 0.0032 & 0.0026 & 0.0017 \\
Bitcoin Cash & -0.0024 & -0.0001 & -0.0003 & $-0.0141^{\mathrm{c}}$ & 0.0105 & 0.0089 & -0.0011 \\
Tether & $7^{*} 10^{-6}$ & -0.0001 & -0.0001 & $0.0002^{\mathrm{b}}$ & 0.0001 & 0.0001 & 0.0001 \\
Stellar & $0.0049^{\mathrm{c}}$ & $-0.0047^{\mathrm{c}}$ & -0.0032 & $-0.0049^{\mathrm{b}}$ & 0.0027 & -0.0019 & -0.0012 \\
Cardano & 0.0006 & -0.0024 & -0.0017 & $-0.0128^{\mathrm{a}}$ & 0.0065 & $0.0118^{\mathrm{b}}$ & -0.0005 \\
Polkadot & 0.0123 & -0.0073 & 0.0059 & 0.0026 & -0.0012 & 0.0081 & 0.0171 \\
Chainlink & 0.0011 & $\mathbf{0 . 0 0 7 8}^{\mathbf{c}}$ & 0.0055 & -0.0067 & 0.0068 & $\mathbf{0 . 0 1 2 2}^{\mathbf{b}}$ & -0.0002 \\
\hline \hline
\end{tabular}

Not: ${ }^{a},{ }^{b} v{ }^{c}$ sirasiyla; $\% 1, \% 5$ ve \%10 anlamlilı düzeylerini ifade etmektedir. Tüm getiri serileri ADF ve PP birim kök testlerine göre seviyesinde durağandır

Tablo 9: GARCH $(1,1)$ Modeli Tanısal İstatistikler

\begin{tabular}{lccc}
\hline \hline Kripto Para & \multicolumn{1}{c}{$\boldsymbol{X}^{\mathbf{2}}$} & DW & ARCH (1) \\
\hline \hline Bitcoin & $\mathbf{1 1 . 5 0 8 4}^{\mathbf{c}}$ & 2.0186 & 0.0005 \\
Ethereum & $\mathbf{1 3 . 9 4 0 3}^{\mathbf{b}}$ & 1.9353 & 0.1464 \\
Ripple & 10.4099 & 1.9147 & 0.1330 \\
Litecoin & $\mathbf{1 2 . 4 3 9 5}^{\mathbf{c}}$ & 1.9755 & 0.0067 \\
Bitcoin Cash & 3.8911 & 1.8662 & $5.5459^{\mathrm{b}}$
\end{tabular}




\begin{tabular}{lccc} 
Tether & 4.0402 & 2.7189 & 0.5383 \\
Stellar & 10.4709 & 1.8718 & 0.0824 \\
Cardano & $23.2689^{\mathrm{a}}$ & 2.0034 & $2.9851^{\mathrm{c}}$ \\
Polkadot & 2.0685 & 1.9839 & 0.0316 \\
Chainlink & $\mathbf{1 0 . 6 6 9 5}$ & 2.0261 & 0.0376 \\
\hline \hline Not: $^{a},{ }^{b}$ ve $^{c}$ sirastyla; $\% 1, \% 5$ & ve \%10 anlamlllk \\
düzeylerini ifade etmektedir.
\end{tabular}

\section{Sonuc}

Bu çalışmada kripto para piyasalarının etkinliği haftanın günü anomalisi açısından araştırılmıştır. Ampirik literatürde ilgili piyasadaki takvim anomalileri genellikle Bitcoin para birimi üzerinden analiz edilmiştir. Bu çalışmada ise Bitcoin'e ek olarak gerek işlem hacmi gerekse piyasa değeri açısından 10 Ocak 2021 itibariyle öne çıkan toplam on kripto paranın getirilerinin zamansal dağılımında takvim anomalilerinin olup olmadığı belirlenmeye çalışılmıştır. Bu amaç doğrultusunda haftanın belirli bir gününün ortalama getirisi ile geri kalan altı gününün ortalama getirisi arasında istatistiksel olarak anlamlı bir fark olup olmadığı kukla değişken katsayısına ilişkin t-istatistiği ve tüm günlerin ortalama getirilerinin birbirine eşit olup olmadığ $\mathcal{X}^{2}$ istatistiği kullanılarak test edilmiştir. Kripto para birimlerinin farklı tarihlerde piyasaya çıkarılmış olmalarından dolayı analizde ele alınan dönem her bir kripto için farklılık göstermektedir.

Analize ilk olarak haftanın her bir günü için ayrı ayrı tahmin edilen kukla değişkenli regresyon modelleri sonuçlarına göre; Bitcoin getirilerinde pozitif pazartesi etkisi, Bitcoin Cash getirilerinde negatif perşembe ile pozitif cuma ve cumartesi etkileri; Tether'de negatif pazartesi etkisi ve son olarak Cardano getirilerinde negatif perşembe ile pozitif cumartesi etkileri olduğu tespit edilmiş̧ir. Ardından sabit terimsiz ve haftanın yedi gününe ilişkin tüm kukla değişkenlerinin yer aldığ regresyon modelleri tahmin edilmiştir. Bu modellerde kukla değişken katsayıları temsil ettiği günün ortalama getirisini ifade etmektedir. Dolayısıyla ilgili katsayıların istatistiksel olarak birbirine eşit olup olmadığı sinanarak kripto getirisinde gün etkisinin olup olmadığ 1 belirlenmeye çalışılmıştır. Modeller değişen varyans problemi nedeniyle ARCH ve $\mathrm{GARCH}$ yöntemleri altında elde edilmiştir. ARCH (1) model sonuçlarına göre; Bitcoin, Ripple, Litecoin, Bitcoin Cash, Stellar ve Cardano; GARCH $(1,1)$ modellerine göre ise; Bitcoin, Ethereum, Litecoin ve Chainlink kripto getirilerinde gün etkisi tespit edilmiştir. Tether ve Polkadot getirilerinde ise haftanın gün etkisinin varlığına ilişkin bulgulara ulaşılmamıştır.

Pazartesi günü etkisi ARCH (1) modeli için Bitcoin'de pozitif ve Ripple ise negatif yönlü olarak saptanmıştır. GARCH $(1,1)$ modeli Bitcoin için bulguları desteklemektedir. Salı günleri ortalama getirilerinde ARCH (1) modelinde Stellar'da kayıplar gözlenirken, GARCH $(1,1)$ modellerine göre Bitcoin, Ethereum ve Chainlink'te daha ortalamanın üstünde kazanç elde edilmektedir. Ripple ve Litecoin ARCH (1) modeline göre çarşamba günleri getiriler artmaktadır. GARCH $(1,1)$ modelinde ise tam tersi bir bulgu elde edilmiş olup Litecoin'de çarşamba günleri kayıplar yaşanmaktadır. ARCH (1) modeline göre ise Ripple, Litecoin, Bitcoin Cash ve Cardano getirilerinde negatif perşembe günü etkisi 
mevcuttur. GARCH $(1,1)$ modeli Litecoin için bu bulguyu desteklerken, Ethereum ortalama getirileri de perşembe günleri azalmaktadır. ARCH (1) modeline göre cuma ve cumartesi günleri Ripple'de kayılar yaşanırken Cardano'da kazançlar mevcuttur. GARCH $(1,1)$ göre ise Bitcoin'de de cuma ve cumartesi günleri getiriler artmaktadır. Ayrıca Ethereum ve Chainlink için cumartesi günleri için benzer bulguya ulaşılmıştır. ARCH (1) modellerinde Litecoin'de pozitif ve Stellar'da ise negatif pazar günü etkisi mevcuttur. GARCH $(1,1)$ modellerinde pazar günü etkisine ilişkin bir bulgu elde edilmemiştir.

Yapılan tüm analizler sonucunda haftanın her bir gününün farklı kripto para cinsleri üzerinde istatistiksel olarak anlamlı bir etkiye sahip oluğu ve Fama (1970) tarafından ileri sürülen Etkin Piyasa Hipotezinin analize dahil edilen 8 kripto para piyasası (Bitcoin, Ethereum, Ripple, Litecoin, Bitcoin Cash, Stellar, Cardano ve Chainlink) için geçerli olmadığ1 bulgusuna ulaşılmıştır. İlgili kripto piyasalarında anormal getiriler gözlenmektedir. Yatırımcılar haftanın belirli günlerinde avantaj sağlayarak ortalamanın üzerinde getiri elde edebilmektedir. Aynı şekilde bazı günlerde ise ortalamanın altında getiriler yani kayıplar söz konusudur. Ayrıca söz konusu kripto para piyasalarında geçmişteki bilgiler kullanılarak gelecek getirilerin tahmin edilmesi mümkün olabilmektedir. Polkadot ve Tether kripto paralarında ise Etkin Piyasa Hipotezi geçerliliğini sürdürmektedir. Analizlerde Bitcoin getirilerinin pazartesi günlerinde artığı tespit edilmiştir. Bu bulgu Aharon ve Qadan (2019) ve Caporale ve Plastun (2019) ile örtüşmektedir. Benzer bulgular Bitcoin piyasası için; Durai ve Paul (2018), Ma ve Tanizaki (2019), ve Caporale ve Plastun (2019, Aharon ve Qadan (2019) ve Evci (2020); Litecoin piyasası için Robiyanto ve diğerleri (2019) tarafindan yapılan çalışmada da ortaya konulmuştur. Bu çalışmada Caporale ve Plastun (2019) ile Ripple ve Yaya ve Ogbonna (2019)'nın aksine ise Ethereum piyasasının etkin olmadığı saptanmıştır.

\section{Kaynaklar}

Abdioglu, Z., Degirmenci, N. (2013). “İstanbul Menkul Kiymetler Borsasında Mevsimsel Anomaliler'. Business and Economics Research Journal, 4(3), 55-73.

Aharon, D. Y., Qadan, M. (2019). “'Bitcoin and the Day of the Week Effect'. Finance Research Letters, 31. 415-425

Ariss, R. T., Rezvanian, R., Mehdian, S. M. (2011). "Calendar Anomalies in the Gulf Cooperation Council Stock Markets', Emerging Markets Review, 12(3), 293-307.

Basher, S. A., Sadorsky, P. (2006). "Day of the Week Effects in Emerging Stock Markets". Applied Economics Letters, 13(10), 621-628.

Baur, D. G., Cahill, D., Godfrey, K., Liu, Z. F. (2019). “'Bitcoin Time of Day, Day of Week and Month of Year Effects in Returns and Trading Volume', Finance Research Letters, 31, 78-92.

Bitcoin. (2021). https://www.bitcoin.com 
Bollerslev, T. (1986). "Generalized Autoregressive Conditional Heteroskedasticity". Journal of Econometrics, 31(3), 307-327.

Caporale, G. M., Plastun, A. (2019). "The Day of the Week Effect in The Cryptocurrency Market'. Finance Research Letters, 31. 258-269.

Chen, G., Kwok, C. C. Y., Rui, O.M. (2000). "The Day of the Week Regularity in the Stock Markets of China". Journal of Multinational Financial Management, 11(2), 139-163.

Cross, F. (1973). "The Behavior of Stock Prices on Fridays and Mondays". Financial Analysts Journal, 29(6), 67-69.

Dangi, V. (2020). "Day of the Week Effect in Cryptocurrencies' Returns and Volatility". Ramanujan International Journal of Business and Research, 5, 139-167.

Dubois, M., Louvet, P. (1996). "The Day of the Week Effect: The International Evidence". Journal of Banking \& Finance, 20(9), 1463-1484.

Durai, S. R. S., Paul, S. (2018). "Calendar Anomaly and the Degree of Market Inefficiency of Bitcoin". Madras School of Economics Working Paper, 168. Erişim: 01.02.2021. http://www.mse.ac.in/wp-content/uploads/2018/05/Working-Paper-16 8. pdf

Decourt, R., Chohan, U. W., Perugini, M. L. (2019). "Bitcoin Returns and the Weekday Effect”. Erişim: 01.02.2021. file:///C:/Users/c/Downloads/SSRN-id34351 76.pdf

Engle, R. F. (1982). "Autoregressive Conditional Heteroscedasticity with Estimates of the Variance of United Kingdom Inflation". Econometrica: Journal of the Econometric Society, 987-1007.

Evci, S. (2020). "Bitcoin Piyasasında Haftanın Günü Anomalisi”. Alanya Akademik Bakış, 4(1), 53-61.

Fama, E. F. (1970). "Efficient Capital Markets: a Review of Theory and Empirical Work". Journal of Finance, 25(2), 383-417.

French, K. R. (1980). "Stock Returns and the Weekend Effect". Journal of Financial Economics, 8(1), 55-69.

Güneysu Atasoy, F., Yamak, N. (2011). “IMKB'de Haftanın Günü Etkisinin Kriz Dönemleri için Araştııılması". Finans Politik ve Ekonomik Yorumlar Dergisi, 48(560), 33-44.

Investopedia. (2021). https://www.investopedia.com

Ke, M. C., Chiang, Y. C., Liao, T. L. (2007). "Day of the Week Effect in the Taiwan Foreign Exchange Market'. Journal of Banking \& Finance, 31(9), 2847-2865.

Kurihara, Y., Fukushima, A. (2017). “The Market Efficiency of Bitcoin: A Weekly Anomaly Perspective". Journal of Applied Finance \& Banking, 7(3), 57-64. 
Kinateder, H., Papavassiliou, V. G. (2019). "Calendar Effects in Bitcoin Returns and Volatility'. Finance Research Letters, 38. Erişim: 01.02.2021. https://doi.org/10.10 16/j.frl.2019.101420

Ma, D., Tanizaki, H. (2019). "The Day of the Week Effect on Bitcoin Return and Volatility'. Research in International Business and Finance, 49, 127-136.

McFarland, J. W., Pettit, R. R., Sung, S. K. (1982). “The Distribution of Foreign Exchange Price Changes: Trading Day Effects and Risk Measurement'. The Journal of Finance, 37(3), 693-715.

Mbanga, C. L. (2019). “The Day of the Week Pattern of Price Clustering in Bitcoin”. Applied Economics Letters, 26(10), 807-811.

Robiyanto, R., Susanto, Y. A., Ernayani, R. (2019). "Examining the Day of the Week Effect and the Month of the Year Effect in Cryptocurrency Market'. Journal Keuangan dan Perbankan, 23(3), 361-375.

Yaya, O. S., Ogbonna, E. A. (2019). “Do we Experience Day of the Week Effects in Returns and Volatility of Cryptocurrency?', MPRA Paper No. 91429, Erişim: 01.02.2021. https://mpra.ub.uni-muenchen.de/91429/1/MPRA_paper_91429.pdf

Yılmaz, F., Akkaya, G. (2020). “Kripto Para Piyasalarında Etkinlik; Haftanın Günü Etkisi: Bitcoin ve Litecoin Örneği'". Girişimcilik İnovasyon ve Pazarlama Araştırmaları Dergisi, 4(8), 166-178.

Zhang, J., Lai, Y., Lin, J. (2017). “The Day of the Week Effects of Stock Markets in Different Countries'. Finance Research Letters, 20, 47-62. 